\title{
IGUALDADE DE OPORTUNIDADES NAS FORÇAS ARMADAS. O PAPEL DAS POLÍTICAS DE INTEGRAÇÃO DE GÉNERO
}

\author{
Helena Carreiras \\ Instituto da Defesa Nacional - Portugal \\ helena.carreiras@eui.eu
}

Recibido: 26-02-2011

Aceptado: 14-04-2011

\section{Resumen}

Neste artigo discute-se o impacto de políticas organizacionais sobre a construção de igualdade de oportunidades e integração de género nas Forças Armadas. Após uma apresentação de dados empíricos que permitem a caracterização global dos factores condicionantes e da situação das mulheres militares nas democracias ocidentais, analisase o papel das políticas organizacionais na promoção da igualdade de oportunidades e integração de género nas Forças Armadas. Conclui-se que nem sempre políticas destinadas a promover a igualdade formal terão idênticos efeitos em termos de integração social, e que as políticas parecem ser condição necessária, mas não suficiente para assegurar maiores níveis de equidade entre sexos no universo militar.

Palabras clave: Género, Forças Armadas, igualdade, políticas de integração.

\begin{abstract}
In this article, the impact of the organizational policies on the construction of the equality of opportunity and integration of the gender in the Armed Forces is discussed. After a presentation of the empirical data that allow the global characterization of the determining factors and the situation of the military women in Western democracies, the paper of the organizational policies in the promotion of the equality of opportunity and gender integration in the Armed Forces is analyzed. The conclusion is that not always the policies destined to promote the formal equality will have identical effects in terms of social integration, and that the policies seem to be a necessary condition, but not enough to assure greater levels of equality between sexes in the military universe.
\end{abstract}

Key words: Gender, Armed Forces, equality, integration policies. 


\section{Introdução}

A participação militar de mulheres, em condições de relativa igualdade com os homens, constitui uma das mais significativas e reveladoras transformações na composição social das Forças Armadas nas sociedades ocidentais durante as últimas décadas. Nesta 'revolução silenciosa', tem sido notória a tendência para uma crescente equalização estatutária, eliminação de restrições formais, crescimento numérico e rotinização da presença feminina nas fileiras. No início do século XXI, todos os países da NATO $^{1}$ tinham admitido e ampliado o número de mulheres nas suas Forças Armadas; muitas restrições foram eliminadas; as mulheres foram progressivamente aceites nas academias e escolas superiores militares e conquistaram o acesso a um conjunto alargado de posições e funções; a consciência da dimensão de género nos processos de integração ampliou-se e politicas concretas com esse objectivo foram concebidas e implementadas em muitos países (Reynaud, 1988; Holm, 1993; Segal, 1999; Carreiras, 2002 e 2006).

Contudo, a integração militar feminina está longe de concretizada. Tal como em muitas outras áreas da vida social, as mulheres ocupam lugares pouco invejáveis nas estatísticas oficiais. Não obstante, a tendência para a eliminação de discriminações e equalização de estatutos entre homens e mulheres, permanecem variadas restrições e as mulheres são ainda largamente excluídas de áreas e funções ligadas ao combate; têm uma representação limitada em posições de poder no sistema militar; nem sempre são aceites e confrontam mesmo reacções hostis. Dados de variados estudos empíricos mostram, de resto, que a elevados patamares de integração formal não correspondem necessariamente idênticos níveis de integração social (Winslow e Dunn, 2002). Por outro lado, progressos registados no passado nem sempre apresentam uma evolução linear: a participação militar feminina tem sido sujeita a ciclos de expansão e contracção (Segal, 1999), e em certos contextos são notórias tendências para reinstituir políticas restritivas (Mitchell,1998; Van Creveld, 2001).

A diversidade entre os países é também muito evidente: enquanto alguns integraram as mulheres, conferindo-lhes um acesso real (e não apenas formal), outros reservam-lhes lugares meramente simbólicos. Entre casos de extrema subrepresentação numérica, segregação do treino e severas restrições funcionais, até casos de ampla representação, padrões de carreira abertos, treino integrado e acesso a papeis de combate,

\footnotetext{
${ }^{1}$ NATO - North Atlantic Treaty Organization.
} 
existe uma pluralidade de situações intermédias. Perante este quadro, importa perguntar: que razões explicam estas diferenças? Que factores subjazem às assimetrias observadas?

Entre a variedade de factores responsáveis pelos diferentes níveis de integração -os quais incluem as condições socio-económicas globais, factores políticos, padrões históricos e culturais, estrutura organizacional militar ou efeitos de tempo- encontramse as políticas institucionais. Sendo certo que a existência ou ausência de políticas, tanto quanto a sua forma e conteúdos, são já o resultado de determinantes externos e/ou organizacionais, uma convicção corrente é a de que políticas organizacionais explícitas constituem um factor crucial para promover a integração de género. Contudo, alguns estudos também revelaram resultados desanimadores no que se refere à eficácia das políticas institucionais na remoção de estereótipos culturais enraizados, que frequentemente funcionam como poderosos obstáculos à integração.

Neste artigo discute-se o impacto de políticas organizacionais sobre a construção de igualdade de oportunidades e integração de género nas Forças Armadas, utilizando dados empíricos de estudos que têm vindo a ser realizados nos últimos anos. Após uma apresentação de dados empíricos que permitem a caracterização global dos factores condicionantes e da situação das mulheres militares nas democracias ocidentais, analisa-se o papel das políticas organizacionais na promoção da igualdade de oportunidades e integração de género nas Forças Armadas. Procura-se aqui contribuir para responder às seguintes questões: qual o impacto das políticas organizacionais sobre a integração de género? Em que medida a existência de políticas de integração explícitas contribui para promover a igualdade nas forças militares? Em que condições são as políticas efectivas e em que condições podem ver os seus efeitos bloqueados?

\section{A situação das mulheres nas Forças Armadas}

\subsection{Factores condicionantes do recrutamento feminino}

O grau e amplitude da participação feminina nas Forças Armadas estão associados a um amplo conjunto de variáveis, cujo impacto relativo se faz sentir em função das condições específicas de cada país em diferentes conjunturas históricas.

Genericamente, podem identificar-se dois tipos fundamentais de factores que se articulam para explicar, em cada caso, os ritmos e características do recrutamento feminino, bem como a definição e implementação de políticas: por um lado, factores de tipo societal e cultural enquadraram o processo e em boa medida criaram as condições 
que o tornaram possível (Reynaud,1988). Referimo-nos à transformação, acentuada a partir de meados do séc. XX, do modelo de participação social e política das mulheres, a sua entrada no mercado de trabalho e as pressões democráticas no sentido de valores igualitários e maior equidade; por outro lado, com uma influência bastante mais directa, transformações no seio da própria organização militar, decorrentes do final da Guerra Fria: mudanças tecnológicas, inversão do rácio entre funções de apoio e de combate, fragmentação e especialização ocupacional, fim dos exércitos de massa, constituição de forças voluntárias, profissionalização e redução dos contingentes e ainda transformação das relações de força no plano internacional. Todas estas mudanças determinaram a necessidade de pessoal mais qualificado e sublinharam a dependência da instituição militar face à sociedade em que se insere.

Se a estes aspectos associarmos as tendências para a diminuição das taxas de natalidade e a crise de legitimidade que torna o serviço militar pouco atractivo para as novas gerações, obtemos um quadro bastante completo dos condicionantes do recrutamento militar feminino. Neste contexto, e de forma mais específica, quatro tipos de factores têm sido identificados para explicar os papeis militares das mulheres e as suas alterações: factores socio-económicos, políticos, culturais e militares (Segal, 1995; Kummel, 2002).

Diversos aspectos relacionados com a estrutura social têm impacto no nível de participação feminina nas Forças Armadas. Um dos condicionantes de base refere-se às tendências demográficas e à articulação destas com a situação no mercado de trabalho. É sabido como a carência de mão-de-obra masculina funcionou historicamente como uma importante força motriz da participação feminina no mercado de trabalho nos países ocidentais. Este factor teve uma expressão idêntica no campo militar, onde a menor disponibilidade de homens significou, em geral, uma ampliação das oportunidades para as mulheres. Nas sociedades industriais avançadas elas constituíram em múltiplas circunstâncias uma importante reserva de força de trabalho, no campo civil como no campo militar. A participação das mulheres na economia formal durante a $1^{\mathrm{a}} \mathrm{e}$, sobretudo durante a $2^{\text {a }}$ Guerra Mundial, constituem elucidativos exemplos desta tendência.

Um segundo factor que, do ponto de vista da estrutura social, adquire relevância na explicação dos papéis militares das mulheres, refere-se à participação feminina no mercado de trabalho, a qual, por seu turno, é indissociável do estado da economia. O processo de crescente participação feminina na economia formal na segunda metade do século XX constituiu um dos processos com maior impacto na mudança de valores e atitudes em direcção a uma maior aceitação das mulheres nas diversas áreas da vida social, tornando consequentemente o serviço militar mais compatível com os papéis admitidos às mulheres. $\mathrm{O}$ estado de contracção ou expansão 
da economia, por seu turno, afecta directamente o nível de participação feminina no mercado de trabalho. Alguns autores notaram que, em conjunturas de alto desemprego (sobretudo entre os jovens) a oferta de mão-de-obra masculina é também elevada e, portanto, decrescem as oportunidades para as mulheres (Segal e Segal, 1983). Ao contrário, em períodos de maior expansão económica e baixo desemprego assistiu-se frequentemente a uma ampliação das perspectivas para o recrutamento feminino. Essa foi, por exemplo, a situação registada nos EUA no final da década de 1970, em que os níveis de desemprego baixaram. Quando esse indicador voltou a subir, o recrutamento feminino sofreu um período de estagnação.

Por seu turno, as variáveis militares têm sido consideradas fundamentais na definição dos papéis militares das mulheres. Factores como a situação em termos de segurança nacional - nível de ameaças ou natureza das missões militares - mudança tecnológica, estrutura das forças e políticas de recrutamento, têm tido um enorme impacto sobre a participação militar feminina. Independentemente da por vezes decisiva influência de variáveis macro-sociais na criação das condições que justificaram o apelo militar às mulheres, ou mesmo da luta contra a discriminação ocupacional (casos do Canadá, Alemanha, Reino Unido) - as razões que, do interior da instituição militar originaram o processo, revestiram-se de uma natureza claramente pragmática e instrumental. A integração feminina aconteceu, em geral, em contextos de carência de efectivos, presente ou antecipada, de necessidade de alargar a base social de recrutamento e 'libertar' os homens para a primeira linha (Moskos, Wiiliams, Segal, 2000).

A natureza das missões militares parece também influir sobre a participação militar feminina. A ausência de mulheres das áreas próximas do combate faz supor que quanto maior for a relativa importância do combate, sobretudo terrestre, menor a presença feminina; contrariamente o desenvolvimento de missões de peacekeeping ou de missões similares às funções policiais internas parece estar associado a um maior envolvimento das mulheres. Adicionalmente, diversos aspectos relacionados com a estrutura das forças militares e respectivos sistemas de serviço militar assumem um elevado poder explicativo da variação em termos do recrutamento feminino. O final da conscrição em muitos países e o desenvolvimento de forças exclusivamente voluntárias está historicamente associado a um crescente recurso à força de trabalho feminino.

Entre os factores culturais encontra-se o processo de construção social do género e, portanto, o conjunto de concepções sobre os papéis adequados a homens e mulheres em cada sociedade. Conforme nota Segal (1995: 758), "a saliência concedida a determinados argumentos sobre os papéis militares das mulheres não se baseia numa realidade objectiva, mas sobretudo em valores culturais. Quando as circunstâncias se 
alteram, os efeitos de factos históricos passados sobre os subsequentes papéis militares das mulheres são obscurecidos pela definição e redefinição cultural desses papéis". Mas inclui-se aqui também a configuração dominante dos valores sobre igualdade e diferença. Sociedades mais igualitárias, onde a participação social e política das mulheres se expandiu, são também sociedades mais predispostas a aceitar o desempenho de funções militares pelas mulheres. Por outro lado, entre os factores culturais destaca-se ainda a importância dos valores relativos à família, na medida em que os papéis sociais das mulheres são, em larga medida, afectados pelas expectativas relacionadas com a sua dedicação na esfera familiar.

Finalmente, os factores políticos referem-se à configuração das relações civilmilitares, ao regime político e respectivo quadro jurídico-institucional, à ideologia política dos vários governos e às consequentes políticas relativas às mulheres e minorias, aos níveis de representação feminina nas estruturas de poder ou ainda ao papel assumido pelos diferentes actores políticos - desde os partidos políticos aos grupos de interesse ou aos media - e à forma como estes se relacionam com a instituição militar (Iskra et al., 2002, Kümmel, 2002) .

Da interacção destes vários factores e do seu peso variável em determinados momentos históricos resultará a configuração específica da participação militar feminina em cada sociedade.

\subsection{Práticas e políticas de integração militar feminina: indicadores empíricos}

Dados de um estudo comparativo sobre a participação militar feminina nos países da NATO (Carreiras, 2006) permitem observar de perto a diversidade de padrões de integração militar feminina. Recobrindo contextos socio-políticos heterogéneos, as situações variam entre, por um lado, uma quase total ausência numérica, rigorosas limitações hierárquicas e funcionais ou segregação em termos de treino e, por outro lado, padrões de carreira relativamente abertos, formação integrada e acesso a funções de combate. Uma multiplicidade de factores, entre os que antes se referiram, determinaram, em cada caso, o desenvolvimento do processo e a formulação de políticas.

A figura I, onde se evidencia uma evolução sustentada da representação feminina neste universo, ilustra também a heterogeneidade de situações entre os países. 
Figura I - Evolução da representação feminina nas forças armadas dos países da NATO (1986-2005) (\%)

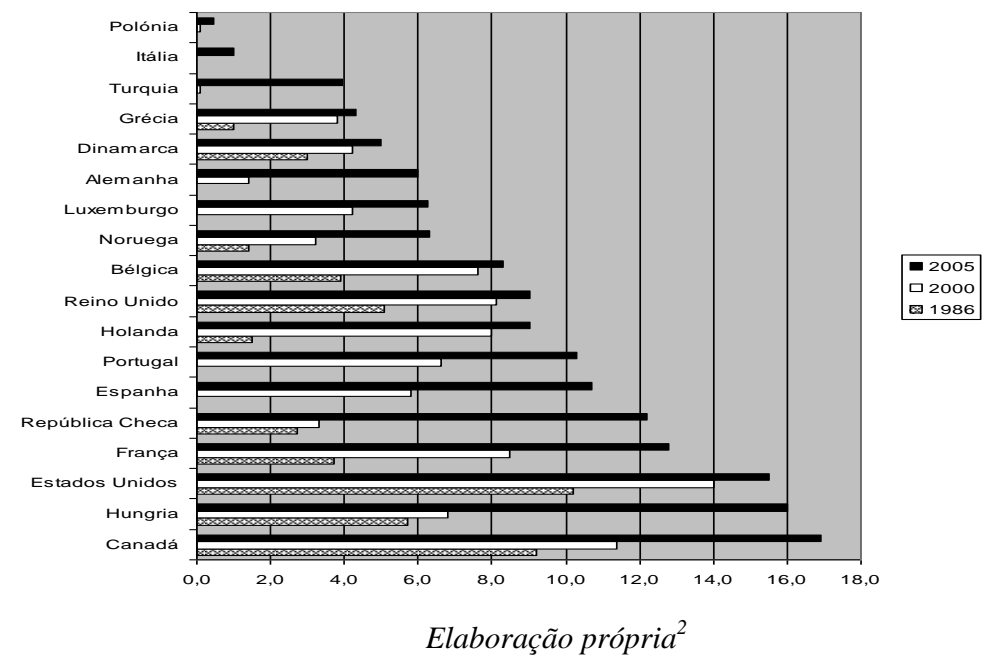

A diversidade observada espelha, desde logo, uma realidade que deve ser tida em conta na análise das diferenças e similaridades entre os países: a temporalidade do processo. Enquanto alguns países iniciaram a integração feminina no início da década de 1970 (Estados Unidos, Canadá, Reino Unido, França), outros seguiram a tendência e abriram progressivamente as suas fileiras às mulheres ao longo das décadas de $1970 \mathrm{e}$ 1980 (por exemplo, a Bélgica, Holanda, Dinamarca e Noruega); um terceiro grupo fê-lo já no início dos anos 1990 (casos de Portugal e Espanha) e finalmente, num dos casos Itália - o processo teve o seu início apenas no ano 2000. É importante o desempenho positivo de Portugal e Espanha em termos de quantitativos de mulheres incorporadas. Deste ponto de vista, ambos os países atingiram patamares surpreendentemente elevados, tendo em conta o 'atraso' com que iniciaram o recrutamento feminino relativamente à maioria dos países analisados.

Do ponto de vista da representação numérica, as políticas variaram em função de determinantes de ordem interna e externa. A maioria dos países instituiu limites máximos de presença feminina, formais ou informais, gerais ou parciais por estabelecimento, especialidade, etc. Casos notórios em que esses máximos formais de recrutamento vigoravam ainda em 2000 são a Turquia onde as mulheres não podiam

\footnotetext{
${ }^{2}$ Fontes: Stanley e Segal, 1988: 563; Carreiras, 2006; Annual Reports of the Committee of Women in the NATO Forces (http://www.nato.int/issues/women_nato/index.html)
} 
constituir mais que $4 \%$ dos cadetes nas Academias Militares, ou a Grécia, onde a mesma percentagem se situava nos $10 \%$.

Noutros casos, porém, as dificuldades de recrutamento forçaram a organização militar não apenas a não impor limites como, pelo contrário, a definir 'objectivos' a atingir em termos da representação feminina. Face a conjunturas económicas favoráveis no mercado de trabalho, bem como a factores relacionados com as condições de serviço no interior das Forças Armadas, o número de candidatos habitualmente diminui e o nível de 'atrição' tende a ampliar-se. Nesta situação, confrontando sérios problemas de recrutamento e retenção, países como a Holanda, Noruega, Dinamarca e Inglaterra desenvolveram, sobretudo ao longo da década de 1990, programas de recrutamento específicos e campanhas promocionais com vista a atrair candidatos femininos.

Se, do ponto de vista da modalidade de recrutamento, todos os países optaram pelo voluntariado, nalguns casos, como na Holanda, na República Checa e na Grécia a conscrição de todos os cidadãos está prevista em caso de guerra ou mobilização. Em países que no dealbar do séc. XXI se baseavam ainda num sistema de conscrição, como era o caso da Noruega e da Dinamarca, ou se encontravam em fase de transição como a França, as mulheres podiam também alistar-se voluntariamente para o cumprimento do serviço militar nas mesmas condições que os conscritos ${ }^{3}$.

No que se refere às funções desempenhadas, enquanto nalguns casos as mulheres se encontravam ainda radical e formalmente excluídas de todas as funções de tipo operacional, como acontecia na Polónia, outros foram pioneiros na eliminação de restrições ao acesso feminino a funções de combate: este foi o caso da Holanda onde em meados da década de 1980 as mulheres puderam pela primeira vez integrar a tripulação de navios de combate. A Dinamarca e a Noruega seguiram pouco depois esta via e colocavam-se, no ano 2000, entre os países que maior abertura proporcionavam. A Noruega foi, aliás, o primeiro país a permitir o serviço feminino em submarinos e desde 1985, as mulheres puderam aceder a todos as funções de combate. A Dinamarca seguiu-se-lhe, eliminando todas as restrições ocupacionais em 1988, após experiências conduzidas com sucesso ao nível das armas combatentes. Embora na sequência desta abertura as mulheres tenham vindo a servir na maioria das funções operacionais, existiam todavia algumas especialidades a que nenhuma mulher havia ainda acedido em 2000, designadamente os para-rangers e fuzileiros, devido ao não cumprimento dos

\footnotetext{
${ }^{3}$ Curiosamente, na Noruega emergiu mesmo um debate sobre a possível introdução do serviço militar obrigatório para mulheres, como forma de ampliar a representação feminina e promover a igualdade (Nielsen, 2001:26).
} 
requisitos mínimos de entrada. A Inglaterra seguiu o mesmo percurso já no início da década de 1990, abrindo posições a bordo de navios, bem como todas as relativas a pessoal navegante na Força Aérea, mas mantendo as restrições em submarinos e nas unidades cuja função principal seja a de "enfrentar e matar o inimigo". Em 2001 a primeira mulher tornou-se comandante de um navio de patrulha.

Num outro extremo, alguns países concentravam o contingente feminino numa única área ou em pouquíssimas especialidades. Essa era, como anteriormente referido, a situação na Polónia, onde praticamente todas as mulheres militares serviam nas áreas de saúde, e também na Alemanha até 2000, onde, por imperativos constitucionais, até essa data as mulheres não podiam desempenhar funções qualificadas como militares, implicando o uso de armas.

Mas, durante este período, sobretudo na década de 1990, as mulheres foram sendo mobilizadas em situações de grande operacionalidade. Por exemplo, durante a Guerra do Golfo, 1100 mulheres inglesas integraram as forças no terreno, juntando-se às 37.000 americanas mobilizadas durante o conflito. Por outro lado, no ano 2000, todos os países da NATO, com excepção da Grécia e da Itália, haviam já enviado mulheres em missões internacionais sob a égide da ONU e da NATO, designadamente em operações de manutenção da paz na ex-Jugoslávia. Os Estados Unidos, país claramente na vanguarda do processo de integração militar feminina, contou com a presença de 11.200 mulheres em operações NATO de manutenção da paz, e em 2002 elas constituíam 8,6\% do pessoal militar americano envolvido em operações no exterior.

Na generalidade dos casos era extremamente limitado o número de mulheres oficiais nos postos mais elevados da hierarquia. Contudo, no final do séc. XX em certos países algumas mulheres haviam já atingido os postos de Coronel (Holanda, Hungria) e General, Brigadeiro ou Vice-Almirante (EUA, Canada, França, Inglaterra). Noutros, não haviam ultrapassado os primeiros degraus da pirâmide hierárquica. Se, de um modo geral, não existiam restrições à progressão profissional e as mulheres podiam formalmente aceder a todos os postos, certos países condicionavam a presença feminina a algumas categorias. Esse era, uma vez mais, o caso da Polónia e Turquia, onde, devido à inexistência de regimes de voluntariado nas categorias de praças, as mulheres apenas podiam aceder aos quadros de oficiais. No Luxemburgo, pelo contrário, as mulheres não se encontravam ainda representadas ao nível de oficiais, integrando exclusivamente as categorias de sargentos e praças. Nestes países, mas também na maioria dos restantes, visto que também permaneciam vedadas às mulheres certas áreas funcionais que permitem o 
acesso aos postos mais elevados, elas acabavam por ser indirectamente interditadas de aceder a esses lugares.

Um elemento interessante diz respeito ao número crescente de situações em que factores exteriores, designadamente a intervenção de tribunais civis, constituiu um elemento chave na transformação de políticas militares, contribuindo para a aceleração do processo de integração e o estabelecimento de condições de igualdade entre homens e mulheres no acesso e exercício da profissão militar. O caso mais evidente é o do Canadá, onde em 1989 um tribunal de direitos humanos decretou que fossem eliminadas todas as restrições existentes ao emprego feminino. Neste caso, o tribunal concedeu às Foças Armadas um período de 10 anos para proceder à total equalização de políticas. Processos semelhantes decorreram de forma mais parcial noutros países (e.g. Holanda e Inglaterra) e verificaram-se mesmo situações de intervenção de tribunais supranacionais. O mais recente e paradigmático exemplo é o da Alemanha, país que, na sequência de uma decisão do tribunal Europeu de Justiça em 2000, aboliu todas as rigorosas limitações ao emprego feminino no Bundeswher. Esta decisão, que certamente ficará nos anais da jurisprudência europeia, obrigou à reinterpretação da constituição alemã a qual explicitamente impedia às mulheres a utilização de armas ${ }^{4}$.

Como consequência destes distintos ritmos e processos os países incluídos nestas comparações detêm diferentes níveis de integração de género. Um índice de inclusividade $^{5}$ construído no âmbito do estudo em referência (Carreiras, 2006), revela claramente esta situação.

\footnotetext{
${ }^{4}$ Sentença do tribunal de 11 de Janeiro de 2000, Tanja Kreil, Caso C285/98.

${ }^{5} \mathrm{O}$ índice incluiu indicadores relacionados com as dimensões de representação global, integração hierárquica e funcional, segregação no treino e políticas de integração.
} 
Figura II - Índice de inclusividade de género nas Forças Armadas (NATO -2000)

$(0=$ menor integração; $19=$ maior integração $)$

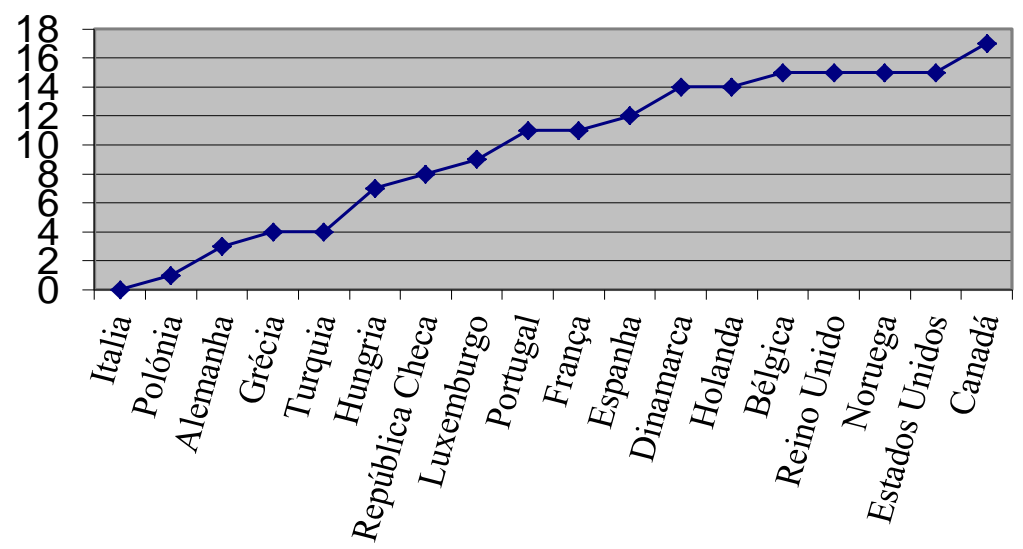

Fonte: Carreiras (2006)

A investigação demonstrou que diversos factores concorrem para explicar as diferenças entre países.

Por um lado, a integração de mulheres nas Forças Armadas atingiu patamares claramente mais elevados em países expostos à democratização das relações de género na sociedade em geral e à existência de pressões externas no sentido de promover a igualdade no interior da instituição militar; onde as forças armadas mais se abriram à sociedade devido a mudanças organizacionais no sentido da profissionalização; onde, finalmente políticas de integração foram propostas e implementadas.

Por outro lado, e independentemente do momento em que as mulheres entraram na instituição, em países onde essas influências externas não se fizeram sentir com a mesma intensidade, onde as forças armadas permaneciam próximas de um modelo de conscrição; onde as mulheres não atingiram posições 'qualificadas' na estrutura social; onde, finalmente, não foram prosseguidas políticas específicas; os níveis de representação e integração de género eram bastante mais reduzidos.

Dados estes resultados, foi possível colocar a hipótese de que a mudança em direcção a maior igualdade nas forças armadas não ocorrerá automaticamente como consequência do tempo ou do aumento do número de mulheres. A redução de assimetrias existentes dependerá muito mais da existência de políticas específicas e da 
forma como factores exteriores determinem orientações e processos de decisão no interior das Forças Armadas.

Neste sentido, uma conclusão possível apontava para a relevância das políticas enquanto factores importantes na promoção da integração de género. Contudo, um olhar mais próximo sobre alguns países-neste caso Portugal e a Holanda- embora confirmasse esta hipótese, introduziu nuances interessantes e mostrou como o processo causal pode ser bem mais complexo, sobretudo quando se trata de avaliar o impacto das políticas.

\section{O efeito das políticas organizacionais sobre a integração de género nas Forças Armadas: um estudo de casos}

Portugal e a Holanda evidenciam diferentes desempenhos em termos de integração de género. Portugal apresenta um padrão mais segregado do ponto de vista da distribuição por ramo e tipo de função, com uma muito menor percentagem de mulheres em funções operacionais. Comparativamente, a Holanda revela uma distribuição muito mais equilibrada das mulheres nos vários ramos e na estrutura ocupacional. Enquanto em Portugal o processo de recrutamento feminino foi marcado por uma perspectiva dominantemente instrumental, consistente com uma generalizada ausência de políticas específicas, a Holanda produziu, desde o início, planos de acção afirmativa que vieram a concretizar-se em políticas activas de gestão da diversidade no seio das Forças Armadas.

Contudo, não obstante as diferentes perspectivas em termos de políticas, os dois países mostram uma inesperada tendência para convergir em aspectos relativamente aos quais poderia esperar-se maiores diferenças: representação numérica e distribuição hierárquica. Tendo iniciado o processo de integração feminina dez anos mais tarde, Portugal revela um desempenho positivo, mostrando uma tendência para acelerar a integração, embora isso aconteça sobretudo nas suas dimensões formais. Alguns indicadores são surpreendentemente positivos dada a ausência de políticas: os níveis globais de representação cresceram rapidamente, a maioria das restrições formais foi eliminada num curto espaço de tempo e o número de mulheres que se candidatam às Forças Armadas continua a ser elevado.

Ao contrário, a Holanda tem um desempenho menos positivo que o esperável, considerando os esforços realizados no sentido de promover a igualdade aos níveis 
governamental e militar. Não apenas as mulheres não parecem sentir-se atraídas pela instituição como os níveis de atrição impedem a sua chegada aos mais elevados lugares hierárquicos. Devido à existência de uma estrutura de oportunidades bastante mais competitiva no mercado de trabalho, progressos anteriormente alcançados em termos de integração de género nas forças armadas não são facilmente sustentados. A existência de políticas, que determinou um clima mais positivo para a integração das mulheres, não parece ser suficiente para mantê-las na instituição.

Em que medida podem estes resultados levar-nos a rever a conclusão relativa ao impacto das políticas, ou, pelo menos, repensar as condições em que a sua eficácia pode ser bloqueada?

Uma resposta possível para esta questão decorre da análise de 54 entrevistas com homens e mulheres oficiais (de diferentes especialidades e postos) nos dois países, realizadas no âmbito do estudo comparativo em análise (Carreiras, 2006). Embora não representativa e naturalmente circunscrita a um universo empírico muito particular, a informação obtida neste âmbito ajudou a resolver o puzzle, ao mostrar como valores culturais relativos às relações entre sexos e aos papéis sociais das mulheres podem limitar os supostos efeitos positivos das políticas, funcionando, assim, como factores de bloqueio no processo de integração de género nas forças armadas.

Ao longo das entrevistas, tanto homens como mulheres fizeram curiosas referências ao impacto das políticas (especialmente na Holanda, onde tais políticas efectivamente existiram). Verificou-se, não apenas uma tendência geral para minimizar a importância de várias medidas e instrumentos de política, como muitas delas foram referidas com suspeita e desconfiança. Isto aconteceu, por exemplo, relativamente aos seguintes aspectos:

- Um forte ressentimento contra o que foi identificado como medidas de 'discriminação positiva' (desde atitudes individuais de tipo proteccionista e paternalista como existência de regras ou padrões organizacionais desenhados especificamente para mulheres);

- Percepções de inequidade derivadas de diferentes critérios de avaliação física;

- Avaliação ambivalente de medidas de part-time;

- Resistência à existência de um sistema de mentores entre as mulheres;

- Desvalorização e rejeição dos cursos destinados a promover a igualdade de género, etc... 
Começando por analisar as entrevistas às mulheres, verifica-se que muitas das oficiais parecem ressentir-se mais de formas de discriminação positiva que de discriminação negativa. Numa primeira análise, este resultado revelou-se surpreendente e paradoxal. Com efeito, a maioria das entrevistadas mostra-se incomodada com as dinâmicas da discriminação positiva, tanto na sua forma organizativa (políticas especificas, regras ou padrões elaborados para as mulheres), como na sua expressão em comportamentos paternalistas ou proteccionistas por parte de alguns homens. Ambas as situações são vistas como factores prejudiciais à plena aceitação das mulheres na medida em que a percepção de injustiça relativa associada a tais formas de tratamento desigual provocam rejeição e atitudes sexistas.

Este ponto de vista é particularmente sublinhado pelas oficiais Portuguesas. Enquanto entre as Holandesas se encontram atitudes mais nuanceadas, as Portuguesas são mais rígidas nos seus julgamentos: “muitas vezes desejei não ser mulher para não ser beneficiada" (Tenente; área de Administração, Marinha Portuguesa, 25 anos).

No caso Holandês, as políticas de discriminação positiva são percepcionadas com suspeição, mesmo quando se admitem os dilemas organizacionais que lhes estão associados:

\begin{abstract}
"Penso que funcionam sempre contra as mulheres. Pode conseguir-se que venham mais mulheres ou que permaneçam mais tempo, mas o grande problema é que as pessoas que já estão nas forças ficam marcadas com o mesmo estigma" (Tenente Coronel; área de electrónica, Força Aérea Holandesa, 39 anos).
\end{abstract}

Curiosamente, mesmo uma medida como o trabalho a tempo parcial tecnicamente disponível para todos, mas efectivamente utilizado esmagadoramente pelas mulheres - pode produzir os mesmos efeitos negativos. Referindo-se a uma outra oficial, promovida em simultâneo, uma capitã do exército Holandês afirma:

"Eu disse-lhe: 'não é justo que sejamos promovidas ao mesmo tempo porque eu trabalhei 5 anos a tempo inteiro e tu apenas a tempo parcial. Porque é que não deverias ficar mais tempo como capitão até seres promovida?' Ok, se tivermos esse tipo de regras as mulheres vão-se embora. Existe sempre uma contradição. Mas dentro de mim, sinto que não é justo (...). Não é possível que ela tenha a mesma experiência que eu quando esteve lá apenas parte do tempo. Ela deveria fazer esse trabalho mais uns anos, talvez não 50\% mas por exemplo 40\% mais" (Capitão; área de logística, Exército Holandês, 33 anos).

Mais que em qualquer outra área, a tensão é ampliada quando estão em causa as capacidades e atributos físicos. Trata-se não apenas de uma das questões 
relativamente às quais mais dificuldades são assinaladas, mas também uma das que suscita maior ambivalência entre as mulheres: "Somos apontadas em termos das provas físicas porque existem critérios diferentes e eu penso que isso não é correcto" (Tenente; área de administração militar; Exército Português).

Um aspecto interessante dos discursos relativos à discriminação positiva refere-se ao facto das mulheres tenderem a ser mais críticas para com as outras mulheres que aceitam ser favorecidas do que para com a organização que desenvolve tais políticas ou para com os homens que adoptam atitudes paternalistas:

"Claro que os homens não gostam disso [discriminação positiva das mulheres]e não posso culpá-los por isso. Se quisermos fazer as mesmas coisas temos que ter os mesmos direitos mas também as mesmas obrigações. Os homens vêem isto e pensam que é injusto: 'vocês são mulheres, podem conseguir tudo facilmente'. Portanto depende de cada mulher. Se ela se comportar do género 'sou uma mulher e posso conseguir tudo o que quero', então acho não será facilmente aceite. Nós temos este poder porque os políticos pensam que é mau que as mulheres abandonem a Força Aérea, e não deveria acontecer. Temos algum poder e eu penso que é mau usarmos esse poder. Se quisermos ter uma organização madura em que as mulheres se sintam bem, não deveríamos fazer esta diferença entre homens e mulheres. Não é justo. Desta forma não podemos ter uma atmosfera agradável” (Capitão, analista de informações da Força Aérea Holandesa, 28 anos).

As posições são também ambíguas relativamente à possibilidade de um sistema de mentores: por um lado, a presença de mulheres mais velhas que poderiam funcionar como modelos é considerada positiva na medida em que mulheres mais jovens poderiam confirmar a possibilidade de progresso; por outro lado, mulheres como superiores podem ser encaradas como ameaçadoras:

"Não é fácil para as mulheres menos graduadas que exista uma mulher superior que pensa saber mais e melhor que qualquer outra pessoa como as coisas são. Se se queixarem a um oficial homem podem ter mais sorte." (Capitão; área de comunicações, Exército Holandês, 41 anos).

Da mesma forma, uma capitã da Força Aérea Holandesa, tendo sentido a necessidade de modelos, revela simultaneamente cepticismo sobre a possibilidade de aceitação desse sistema por parte das mulheres mais jovens:

"O que eu fazia, e deixei de fazer, era ser algo condescendente, o que nunca foi a ideia. Queremos tomar conta delas, avisá-las das coisas, dizer-lhes 'não faças isto ou aquilo', de uma forma amigável, como uma irmã mais velha. Algumas aceitavam isso bem, outras não e olhavam para mim com um ar do tipo 'mas quem julgas que és? Não me interessa o que pensas'. Depois dei-me conta que isto era discriminação...que fazia isso com elas e não com os rapazes. É uma espécie de comportamento condescendente que nunca foi intencional e dei-me conta que era ridículo; quando os homens fazem isso 
connosco odiamos, e eu estava a fazer o mesmo" (Capitã; piloto de helicóptero; Força Aérea Holandesa; 39 anos).

Por vezes, determinadas decisões da organização podem também conduzir à intensificação de conflitos. Isto é exemplificado pelo caso de uma tenente da Marinha Portuguesa, colocada num navio numa posição que em princípio não estaria qualificada para assumir, mas porque, existindo mulheres praças a bordo, houve a necessidade de integrar uma oficial para as enquadrar.

"Só os melhores para lá vão. Se me dissessem 'vais para lá porque tiveste um bom desempenho e é o teu próprio mérito' eu ficava muito feliz. Assim, é terrível, porque quando eu chegar lá vou ter problemas com os outros oficiais. Eles estão lá porque mereceram. Eu estou lá porque sou uma mulher. Terei que lhes dizer que têm toda a razão" (Tenente, classe de Marinha, Marinha Portuguesa, 24 anos).

Por parte de alguns dos oficiais homens, existe também uma forte reacção contra o que é identificado como 'discriminação positiva' das mulheres, especialmente por parte dos oficiais mais jovens. O sentimento de privação relativa é frequente: muitos destes oficiais não entendem porque não podem também usufruir de certos 'privilégios', designadamente um tratamento preferencial por parte de superiores, chuveiros especiais, etc. Outros queixam-se de competição desleal, no que se refere, por exemplo, ao grau de exigências nos requisitos físicos:

\footnotetext{
"Sempre me revoltou [...], os testes físicos de entrada serem diferentes. Eu tive amigos meus que queriam ser pilotos e que se calhar não entraram para entrar uma mulher, que se calhar tinha menos capacidade. Isso irritava-me profundamente e irrita-me profundamente. A parte física é completamente diferente e eu não compreendo porque é que há-de ser assim. Eu acho, sim senhora, deve ser aberto às mulheres, não compreendo sequer porque é que se criam restrições às mulheres irem para postos de combate, acho que são iguais, têm é que fazer o mesmo que nós"(Tenente, Pilotagem; Força Aérea Portuguesa, 27 anos)
}

Outros ainda acreditam que a presença de mulheres é a razão pela qual os níveis de exigência são reduzidos, o que é negativo para a instituição como um todo. Entre os oficiais Holandeses encontramos, contudo, um discurso mais sofisticado sobre o tema da discriminação positiva. Preferem explicar a desadequação ou insucesso de algumas mulheres em termos de deficiências de selecção e treino, ou seja, identificando responsabilidades organizacionais mais que individuais. Muitos dos erros apontados são considerados resultado de pressões políticas para o recrutamento feminino. De acordo com vários testemunhos, o nível de exigência foi reduzido e as mulheres não tiveram 
que respeitar critérios de selecção existentes. Consequentemente, teriam sido designadas para funções que não poderiam cumprir, o que, por seu turno, teria gerado avaliações negativas e estigmatização:

“[...] elas não conseguiam fazer o seu trabalho; não era culpa delas porque não eram adequadas para essas funções; isso tem um efeito negativo que dura por muitos anos." (Capitão; área de administração; Exército Holandês; 42 anos).

"[...] as mulheres têm menos competências que os homens porque tiveram que vir para a organização" (Tenente; logística; Marinha Holandesa; 33 anos).

Todas estas referências sugerem uma possibilidade perturbadora no que diz respeito à avaliação de programas e políticas: a de que a eficácia das políticas é limitada pela forma como os indivíduos as interpretem; ou, mais ainda, que nem sempre políticas destinadas a promover a igualdade formal terão idênticos efeitos em termos de integração social. Valores culturais relativos à masculinidade, à feminilidade e aos papeis sociais das mulheres podem funcionar como decisivos obstáculos no processo de integração feminina, mesmo quando todas as outras condições são favoráveis.

\section{Conclusão}

Os dados analisados neste artigo reforçam a hipótese de que se os militares se sentirem fortemente pressionados pelas políticas institucionais, ou se estas forem interpretadas por homens e mulheres como fontes de inequidade; resistências explícitas à integração feminina podem diluir-se, mas apenas para ser substituídas por formas mais encobertas de discriminação e hostilidade. Políticas organizacionais que desencorajam comportamentos negativos contra as mulheres militares podem não ser tão vitais como muitos supõem para o sucesso ou fracasso dos processos de integração.

Neste sentido, as políticas podem ser condição necessária, mas não suficiente para a integração. O seu impacto, enquanto positivo na integração formal, pode não sêlo necessariamente em termos de integração social e as condições para a mudança não dependem estritamente das políticas formais. Maior inclusividade será porventura mais o resultado de mudanças em termos de participação social e política das mulheres, do seu impacto sobre concepções culturais sobre papéis de género e correlativas práticas sociais. 
Estas conclusões não devem, contudo, ser interpretadas no sentido de desvalorizar a existência, implementação e monitorização de políticas por três razões fundamentais.

Desde logo, a ideia de que as políticas podem ser uma condição necessária, mas não suficiente para garantir a sustentabilidade do processo de integração de género nas forças armadas, exige o desenvolvimento de pesquisas especificamente desenhadas para avaliar o impacto das políticas, o que não foi objectivo dos estudos referenciados neste trabalho.

Por outro lado, essa ideia parece coincidir com determinadas perspectivas de análise que sublinham os limites das políticas formais na mudança cultural (Katzenstein e Reppy, 1999), mas que também sugerem que o verdadeiro problema é o choque entre aspectos da cultura militar que promovem a intolerância e as políticas oficiais de promoção da igualdade de género, e não necessariamente a ausência ou inadequação das políticas.

Finalmente, a existência de alguns resultados empíricos contraditórios, ou seja, relatos de situações em que as políticas institucionais parecem ter ajudado efectivamente a alterar atitudes negativas relativamente às mulheres militares (Yoder, Adams e Prince, 1983; Rosen et. al., 1996), alerta contra conclusões lineares. Sugere, ao contrário, a necessidade de analisar as condições sob as quais a eficácia das políticas pode variar, considerando tanto variáveis externas (como por exemplo, a sua ancoragem institucional, articulação ou conflito com políticas de género noutros contextos) e características internas (flexibilidade vs. rigidez, estabilidade vs volatilidade, coerência, coordenação, formas de implementação e controle).

Nesta medida, tão crucial como propor e implementar este tipo de políticas, será garantir que elas não irão colidir com orientações e valores dos militares, ou pelo menos (na medida em que alguma colisão pode ser inevitável) que sejam compreendidas e genericamente aceites. Caso contrário, os resultados poderão ser irrelevantes ou mesmos prejudiciais à integração de género.

Esta conclusão pode parecer algo desanimadora no que se refere à possibilidade de utilização de políticas na eliminação de obstáculos à integração de género. Contudo, não há razão para acreditar que a igualdade será atingida ou que as percepções se modificarão na ausência de igualdade formal e representação justa. E, pelo menos no que concerne à igualdade formal, as políticas são fundamentais. Se atingir posições objectivas na estrutura social não assegura a igualdade (ou seja, não é uma condição suficiente), não as atingir garante, seguramente, a reprodução das desigualdades. 


\section{BIBLIOGRAFÍA}

- Carreiras, H. (2002): Mulheres em Armas. A Participação Militar Feminina na Europa do Sul. Lisboa: Cosmos/IDN.

. (2006): Gender and the Military. Women in the Armed Forces of Western Democracies. London: Routledge.

- Holm, J. (1993): Women in the Military: an Unfinished Revolution. Novato, Calif.: Presidio Press.

- Iskra, D.; Trainor, S.; Leithauser, M. e Segal, M. W. (2002): "Women's Participation in Armed Forces Cross-Nationally: Expanding Segal's Model". En Current Sociology vol. $50, \mathrm{n}^{\circ}, 5$, pp.771-97.

- Katzenstein, M. F. e Reppy, J. (eds.) (1999): Beyond Zero Tolerance, Discrimination in Military Culture. Lanham: Rowan \& Littlefield Publishers.

- Kümmel, G. (ed.) (2002): "Women in the Armed Forces of the World: Recent Trends and Explanations", Current Sociology, vol. 50, $\mathrm{n}^{\circ}$. 5, pp. 611-797, (Número monográfico).

- Mitchell, B. (1998): Women in the Military, Flirting With Disaster. Washington: Regnery Publishing.

- Moskos, C. C.; Williams, J. A. e Segal, D. R. (orgs.) (2000): The PostModern Military. New York: Oxford University Press.

- Nielsen, V. (2001): “Women in uniform”. En NATO Review, vol. 49, n'. 2, pp. 26-27.

- Reynaud, E. (1988): Les Femmes, la Violence et l'Armée. Paris: Fondation pour les Études de Defense Nationale.

- Rosen, L. N. et al. (1996): "Cohesion and Readiness in Gender-Integrated Combat Service Support Units: the Impact of Acceptance of Women and Gender Ratio". En Armed Forces and Society, vol. 22, n'. 4, pp. 537-553.

- Segal, M. W. (1995): “Women's military roles cross-nationally - Past, Present and Future”. En Gender \& Society, vol. 9, n’. 6, pp.757-775.

. 1999. "Gender and the Military". En J. S. Chafetz (ed.): Handbook of the Sociology of Gender, New York: Kluwer Academic/Plenum Publishers, pp. 563-582.

- Segal, M. W. e Segal, D. R. (1983): "Social Change and the Participation of Women in the American Military". En Research in Social Movements, Conflicts and Change, vol. 5. Greenwich: JAI Press, pp. 235-258.

- Stanley, S. C. e Segal, M. W. (1988): "Military Women in NATO: an Update". En Armed Forces and Society, vol. 14, nº . 4, pp. 559-585.

- Van Creveld, M. (2001): Men, Women and War. Do Women Belong in the Front Line? 
London: Cassell\&Co.

- Winslow, D. e Dunn, J. (2002): "Women in the Canadian Forces: Between Legal and Social Integration”. En Current Sociology, vol. 50, nº 5, pp. 641-67.

- Yoder, J. D.; Adams, Jerome e Howard, Prince (1983): "The Price of a Token". En Journal of Political and Military Sociology, vol. 11, nº. 2, pp. 325-37. 